\title{
DIFFERENT INTERPRETATIONS OF THE COST-EFFECTIVENESS OF RENEWABLE ELECTRICITY SUPPORT: SOME ANALYTICAL RESULTS ${ }^{1}$
}

Emilio Cerdá

Universidad Complutense

Madrid, Spain

Email: ecerdate@,ccee.ucm.es
Pablo del Río

National Research Council of Spain (CSIC)

Madrid, Spain

Email: pablo.delrio@csic.es

\section{January, 10, 2014}

\begin{abstract}
The costs of support for electricity from renewable energy sources are an issue of concern for governments all over the world. The cost-effectiveness of such support is one of the main criteria to assess the success of policy instruments. However, significant confusion exists in the literature about which costs should be minimised. Some authors define the concept of cost-effectiveness as that which minimises the generation costs of renewable energy. Others define it as that which minimises the costs of support. In this paper, the optimisation problems corresponding to each of the approaches are formally stated, the corresponding optimality conditions are obtained, the optimal solutions of both approaches are compared and some mechanism of transfer of rents from consumers to producers, with good properties, are proposed.
\end{abstract}

Key words: renewable electricity, cost-effectiveness, analytical results

\footnotetext{
${ }^{1}$ Financial support from the Ministerio de Economía y Competivividad (Project ECO2012-39553-C0401 ) is acknowledged. We thank Barry Readman for the linguistic revision of the text.
} 


\section{Introduction}

The costs of support for electricity from renewable energy sources (RES-E) are an issue of important concern for governments worldwide (International Energy Agency (IEA), 2011). In the European Union, in every Member State, support schemes are being adjusted, and such reforms are needed in order to ensure their cost-effectiveness (European Commission 2012).

The main criteria to assess the success of policy instruments of support for RESE are effectiveness (achievement of a certain target) and cost-effectiveness (the achievement of the target at the lowest possible cost).

Which costs should be minimised? The answer depends on the approach being adopted. Some authors define the concept of cost-effectiveness as that which complies with the equimarginality principle, i.e., minimisation of RES-E generation costs. Many others, including important organisations (European Commission, International Energy Agency, Intergovernmental Panel on Climate Change) define it as "the lowest costs of support" generally equating it with the minimisation of consumer costs.

Rarely do supporters of one approach argue along the same lines as those of the other approach. Those defending the minimisation of RES-E generation costs do not usually mention support costs, whereas those supporting the minimum policy costs approach seldom argue in favour of minimisation of generation costs. This is an important issue to analyse, bearing in mind that both approaches have been used and will be used to justify different types of policies (instruments and design elements). It is particularly important in the European Union, where there is a lively debate on the harmonisation or non-harmonisation of support schemes and the instruments that would be more "cost-efficient" to implement (see European Commission 2012, Council of European Energy Regulators (CEER) 2012, del Río et al 2012, among others). 
In del Río and Cerdá (2014) the policy implications of these different interpretations of the cost-effectiveness of renewable electricity support are studied. The minimum generation cost approach tends to favour technological-neutrality in RES-E support and usually advocates the use of Tradable Green Certificates schemes without banding. In contrast, the "minimum policy costs" approach favours technology-specific instruments and, in particular, Feed-in tariffs with support levels differentiated by technologies.

The objectives of this paper are the following: a) to state formally the mathematical problems corresponding to each of the approaches, b) to obtain the optimality conditions for each of those problems, c) to relate the optimal solution of both approaches, d) to propose some mechanisms of transfer of rents from consumers to RES-E producers, for which the optimal solution in both approaches is the same.

The methodology of this paper is based on formal analysis. Some analytical results are presented. We restrict our analysis to the RES-E sector, i.e., we do not take into account either the effects on the whole electricity system or impacts on the economy as a whole ${ }^{2}$. For the sake of simplicity, we further assume that it is electricity consumers who pay for RES-E support (i.e., not taxpayers), which is generally the case, at least in the EU (Teckenburg et al 2011, del Río et al 2012). They pay a surcharge for the RES-E policy in their electricity bills.

The paper is structured as follows. The next section refers to cost-effectiveness as minimisation of RES-E generation costs. In Section 3, the cost-effectiveness as minimisation of consumer costs is studied. The relationship between both approaches is analysed in Section 4. Some interesting mechanisms of transfer of rents from consumers to RES-E producers are proposed in Section 5. Section 6 concludes.

\footnotetext{
${ }^{2}$ In particular, we disregard the so-called merit-order effects.
} 


\section{Cost-effectiveness as minimisation of RES-E generation costs}

Several contributions in the RES-E literature have followed this approach, including Schmalensee (2011), Fürsch et al (2010), Green and Yatchew (2012), Borenstein (2011), Joskow (2011), Heal (2010) and Aune et al (2012) ${ }^{3}$.

In this paper, we consider levelized costs of RES-E generation. Levelized costs can be defined as the "ratio of total lifetime expenses versus total expected outputs, expressed in terms of the present value equivalent" (Nuclear Energy Agency and International Energy Agency, 2005). Therefore, levelized cost is the price at which electricity must be generated from a specific source to break even over the lifetime of the project. It is an economic assessment of the cost of the energy-generating system, including all the costs over its lifetime: initial investment, operations and maintenance, cost of fuel, cost of capital and an assumed rate for each plant type, and is very useful in calculating the costs of generation from different sources.

Levelized costs form the basis of much of the discussion in policy circles over the costs of different technologies for electricity generation and have been estimated frequently over the last twenty-five years (Allan et al, 2011).

In what follows, we formally define the mathematical problem at hand.

Let us assume that we have technologies and locations $1,2, \ldots, n$.

For each $i \in\{1,2, \ldots, n\}$,

$q_{i}$ is the quantity produced. It is assumed that $0 \leq q_{i} \leq \bar{q}_{i}$, where $\bar{q}_{i}>0$ is the maximum quantity which can be produced with technology and location $i$ because of physical and technical constraints.

\footnotetext{
${ }^{3}$ An example of the line of reasoning of this approach is the following sentence in Schmalensee (2011, p.9): "Ex post efficiency as regards the top-line twenty percent target requires E.U.-wide equalization of the marginal cost of producing electricity from renewable energy".
} 
$C_{i}\left(q_{i}\right)$ is the total generation cost corresponding to technology and location $i$. It is assumed that $C_{i}\left(q_{i}\right)$ is a non-negative function, of class $C^{(2)}$ and convex (that is $\left.C_{i}^{\prime \prime}\left(q_{i}\right) \geq 0\right)$.

$Q=\sum_{i=1}^{n} q_{i}$ is the total quantity of renewable electricity generated, using technologies and locations $1,2, \ldots, n$.

$C\left(q_{1}, q_{2}, \ldots, q_{n}\right)=\sum_{i=1}^{n} C_{i}\left(q_{i}\right)$ is the RES-E total generation cost.

Let us assume that a RES-E target $Q^{*}$ is given.

Then, the problem to be solved, if the objective is the minimization of the RESE generation costs is the following:

\section{$\underline{\text { Problem } 1}$}

$$
\begin{aligned}
& \underset{q_{1}, q_{2}, \ldots, q_{n}}{\operatorname{Min}} C\left(q_{1}, q_{2}, \ldots, q_{n}\right)=\sum_{i=1}^{n} C_{i}\left(q_{i}\right) \\
& \text { subject to: } \sum_{i=1}^{n} q_{i}=Q^{*} \\
& \quad 0 \leq q_{i} \leq \bar{q}_{i}, \text { for } i=1,2, \ldots, n \\
& \text { where } Q^{*}>0 \text { is given. }
\end{aligned}
$$

The conditions defining the optimal solution of Problem 1 are presented in the following Proposition. 


\section{Proposition 1.}

The optimal solution of Problem $1\left(q_{1}^{*}, q_{2}^{*}, \ldots, q_{n}^{*}\right)$, is characterised by the following conditions: $\quad \sum_{i=1}^{n} q_{i}^{*}=Q^{*}$, with:

$$
\begin{aligned}
& q_{i}^{*}=0, \text { if } C_{i}^{\prime}(0) \geq \lambda^{*}, \\
& q_{i}^{*}=\bar{q}_{i}, \text { if } C_{i}^{\prime}\left(\bar{q}_{i}\right) \leq \lambda^{*}, \\
& q_{i}^{*} \in\left(0, \bar{q}_{i}\right), \text { if } C_{i}^{\prime}\left(q_{i}^{*}\right)=\lambda^{*},
\end{aligned}
$$

where $\lambda^{*}=\frac{d C^{*}}{d Q}=M C^{*}$.

The proof is in the Appendix.

The interpretation of the optimality conditions is the following:

- Those technology segments and sites with marginal costs above $M C^{*}$ would not be deployed at all (1).

- Technology segments and sites for which the marginal cost of last unit is less than (or equal to) $M C^{*}$ have to be used in their entirety (2).

- The rest of the technologies and sites have to be deployed until the marginal cost curve intersects $M C^{*}(3)$.

Therefore, the set of all technologies and locations $\{1,2, \ldots, n\}$ can be partitioned in the following way:

$\{1,2, \ldots, n\}=J_{N} \cup J_{B} \cup J_{E}$,

where $J_{N}=\left\{i: C_{i}^{\prime}(0) \geq M C^{*}\right\}, \quad J_{B}=\left\{i: C_{i}^{\prime}\left(\bar{q}_{i}\right) \geq M C^{*}\right\}$ and $J_{E}=\left\{i: C_{i}^{\prime}\left(q_{i}^{*}\right)=M C^{*}\right\}$.

If $i \in J_{N}$, technology and location $i$ would not be deployed.

If $i \in J_{B}$, technology and location $i$ would be fully deployed until reaching its bound.

Technologies and locations $i \in J_{E}$, would be deployed until their respective marginal cost curve intersects $M C^{*}$.

Some authors define the concept of cost-effectiveness as that which complies with the "equimarginal" principle, as defined in the environmental economics literature (see 
Tietenberg, 2008) $)^{4}$. However, in accordance with Proposition 1, strictly speaking, equimarginality is only satisfied for technologies and sites belonging to the set $J_{E}$.

In case there are no bounds to the quantity to be deployed for each technology/location, the cost-effectiveness solution can be obtained easily as a corollary of the previous proposition.

\section{Corollary 1.}

If in Problem 1, the constraints $q_{i} \leq \bar{q}_{i}$, for $i=1,2, \ldots, n$. are removed, the optimal solution of the problem $\left(q_{1}^{*}, q_{2}^{*}, \ldots, q_{n}^{*}\right)$, is characterised by the following conditions: $\sum_{i=1}^{n} q_{i}^{*}=Q^{*}$, with:

$$
\begin{gathered}
q_{i}^{*}=0, \text { if } C_{i}^{\prime}(0) \geq \lambda^{*}, \\
q_{i}^{*} \in\left(0, \bar{q}_{i}\right), \text { if } C_{i}^{\prime}\left(q_{i}^{*}\right)=\lambda^{*},
\end{gathered}
$$

where $\lambda^{*}=\frac{d C^{*}}{d Q}=M C^{*}$.

The proof is in the Appendix.

\section{Cost-effectiveness as minimisation of consumer costs}

Many contributions in the RES-E literature follow this approach, including Haas et al (2011), Verbruggen (2009), Verbruggen and Lauber (2012), Klessmann et al (2011), Huber et al (2004), Bergek and Jacobsson (2010), Ragwitz et al (2007), European Commission (2008, 2012), Steinhilber et al (2011), Resch et al (2009),

\footnotetext{
4 "The least cost means of achieving an environmental target will have been achieved when the marginal costs of all possible means of achievement are equal" (Tietenberg, 2008, p. 18).
} 
Mitchell et al (2011), IEA (2008), IEA (2011), Mendonza (2007), Couture and Gagnon (2009) and de Jager et al (2011) .

Renewable energy technologies compete with other conventional generation technologies as well as with each other in order to penetrate the electricity market. However, since their private costs are generally higher than the private costs of the conventional energy sources, they require financial support ${ }^{6}$. This can be provided through different instruments. We are assuming that electricity consumers (not the taxpayers) pay the RES-E support. Thus, a goal for policy makers could be to have a certain penetration of RES-E (at the level of $Q^{*}$ ) at the minimum costs for consumers.

Rents or profits, defined as transfers from consumers to producers above RESE generation costs, have to be considered. Some surplus is needed in order to make future RES-E investments attractive. Producers use short-term rents to pay for investment costs (Hirth and Ueckert, 2012) and therefore, reducing generators' rents too much might leave them in a situation where they cannot pay back the investments they have made and go bankrupt.

For the minimization of the policy costs approach, the aim is to minimise total consumer costs, which is the addition of the total amount of rent transferred from electricity consumers to producers above RES-E generation costs and generation costs.

Let us define formally the corresponding problem:

To all the variables, functions and parameters introduced in Section 2, we add the following functions:

\footnotetext{
5 An example of the line of reasoning of this approach is the following sentence in Mitchell et al (2011, p.55): "Static efficiency can be measured as cost-effectiveness or a comparison of total support received relative to generation costs".

${ }^{6}$ Private cost estimates for new capacity are levelized costs: they reflect the present discounted value of the total cost of constructing, maintaining, and operating an electricity-generating plant over its entire lifetime and are expressed in terms of real cents per $\mathrm{kWh}$ (Greenstone and Looney 2012). The private plus the external costs of energy use (i.e., the negative impacts of energy use on health, the environment and national security) leads to the social cost of energy use.
} 
$T_{i}\left(q_{i}\right)$ is the total amount of rent transferred from electricity consumers to producers above RES-E generation costs for technology and location $i \in\{1,2, \ldots, n\}$. It is assumed that $T_{i}\left(q_{i}\right)$ is a non-negative function, of class $C^{(2)}$ and that $T_{i}+C_{i}$ is convex (that is $\left.T_{i}^{\prime \prime}\left(q_{i}\right)+C_{i}^{\prime \prime}\left(q_{i}\right) \geq 0\right)$

$T\left(q_{1}, q_{2}, \ldots, q_{n}\right)=\sum_{i=1}^{n} T_{i}\left(q_{i}\right)$ is the total amount of rent transferred from electricity consumers to RES-E producers above generation costs.

The problem to be solved, if the objective is the minimization of consumer costs is the following:

\section{Problem 2A}

$$
\begin{aligned}
& \underset{q_{1}, q_{2}, \ldots, q_{n}}{\operatorname{Min}} \tilde{C}\left(q_{1}, q_{2}, \ldots, q_{n}\right)=T\left(q_{1}, q_{2}, \ldots, q_{n}\right)+C\left(q_{1}, q_{2}, \ldots, q_{n}\right)=\sum_{i=1}^{n} T_{i}\left(q_{i}\right)+\sum_{i=1}^{n} C_{i}\left(q_{i}\right) \\
& \text { subject to: } \\
& \qquad \sum_{i=1}^{n} q_{i}=Q^{*} \\
& \qquad 0 \leq q_{i} \leq \bar{q}_{i}, \text { for } i=1,2, \ldots, n
\end{aligned}
$$

where $Q^{*}>0$ is given.

The conditions to be satisfied by the optimal solution of Problem 2A are presented in Proposition 2.

\section{Proposition 2.}

The optimal solution of Problem $2 A\left(q_{1}^{+}, q_{2}^{+}, \ldots, q_{n}^{+}\right)$, is characterised by the following conditions: $\quad \sum_{i=1}^{n} q_{i}^{+}=Q^{*}$, with:

$$
\begin{aligned}
& q_{i}^{+}=0, \text { if } T_{i}^{\prime}(0)+C_{i}^{\prime}(0) \geq \tilde{\lambda}^{+}, \\
& q_{i}^{+}=\bar{q}_{i}, \text { if } T_{i}^{\prime}\left(\bar{q}_{i}\right)+C_{i}^{\prime}\left(\bar{q}_{i}\right) \leq \tilde{\lambda}^{+}, \\
& q_{i}^{+} \in\left(0, \bar{q}_{i}\right), \text { if } T_{i}^{\prime}\left(q_{i}^{+}\right)+C_{i}^{\prime}\left(q_{i}^{+}\right)=\tilde{\lambda}^{+},
\end{aligned}
$$


where $\tilde{\lambda}^{+}=\frac{d \tilde{C}\left(q_{1}^{+}, q_{2}^{+}, \ldots, q_{n}^{+}\right)}{d Q}$

The proof of Proposition 2 is immediate, given Proposition 1 and the similarity between problems 1 and $2 \mathrm{~A}$.

However, the solution of Problem 2A does not imply that the problem of minimisation of consumer costs is solved, because in Problem 2A the functions $\left(T_{1}, T_{2}, \ldots, T_{n}\right)$, that is the specific mechanism of transfer of rents from consumers to producers, is given. But a specific mechanism may not be adequate to minimise the consumer costs, even if the optimality conditions for Problem 2A are applied. Then, a second stage has to be introduced, in order to minimise total consumer costs.

Let us assume that a set of mechanisms of transfer of rents from electricity consumers to RES-E producers $\left(T_{1}^{j}, T_{2}^{j}, \ldots, T_{n}^{j}\right)$, for $j \in J$, where each element $j$ of the family verifies the assumptions introduced in the statement of Problem 2A, is given.

Then, the following problem has to be solved:

Problem 2B:

$$
\begin{gathered}
\min _{j \in J}\left(\tilde{C}^{j}\right)^{*} \\
\text { where }\left(\tilde{C}^{j}\right)^{*}=\tilde{C}^{j}\left(q_{1}^{+}, q_{2}^{+}, \ldots, q_{n}^{+}\right)=\sum_{i=1}^{n} T_{i}^{j}\left(q_{i}^{+}\right)+\sum_{i=1}^{n} C_{i}\left(q_{i}^{+}\right),
\end{gathered}
$$

and $\left(q_{1}^{+}, q_{2}^{+}, \ldots, q_{n}^{+}\right)$is the optimal solution of Problem 2A for the mechanism

$$
\left(T_{1}^{j}, T_{2}^{j}, \ldots, T_{n}^{j}\right)
$$

Therefore, in order to minimise the total policy costs, the following steps have to be followed: 
1. Define a set of mechanisms $\left(T_{1}^{j}, T_{2}^{j}, \ldots, T_{n}^{j}\right)$, for $j \in J$. Each mechanisms $j \in J$ has to give producers enough surplus to make future RES-E investments attractive.

2. For each mechanism $j \in J$, solve Problem 2A.

3. Solve Problem 2B.

Then, a mechanism $j^{*} \in J$ is chosen, and a vector of optimal quantities $\left(q_{1}^{+}, q_{2}^{+}, \ldots, q_{n}^{+}\right)$is obtained, with $\sum_{i=1}^{n} q_{i}^{+}=Q^{*}$, corresponding to the optimal solution of Problem 2A for the mechanism $\left(T_{1}^{j^{*}}, T_{2}^{j^{*}}, \ldots, T_{n}^{j^{*}}\right)$. The total cost to be paid by electricity consumers is equal to $\tilde{C}^{j^{*}}\left(q_{1}^{+}, q_{2}^{+}, \ldots, q_{n}^{+}\right)=\sum_{i=1}^{n} T_{i}^{j^{*}}\left(q_{i}^{+}\right)+\sum_{i=1}^{n} C_{i}\left(q_{i}^{+}\right)$.

\section{Relationship between both approaches}

In this Section, we will use some counterexamples to show that 1) minimisation of generation costs does not imply that consumer costs are minimised, and, 2) minimisation of consumer costs does not imply that generation costs are minimised.

\subsection{Minimisation of generation costs does not imply that consumer costs are minimised}

Let us assume that generation costs are minimised. This does not imply that consumer costs are also minimised (del Río and Cerdá, 2014). Let us justify this with a simple example.

Let us assume that the aggregated RES-E marginal generation costs are given by the function: 


$$
M C_{a}(Q)=\left\{\begin{array}{lc}
C_{3}^{\prime}(Q), & \text { if } 0 \leq Q \leq \bar{q}_{3} \\
C_{2}^{\prime}(Q), & \text { if } \bar{q}_{3}<Q \leq \tilde{Q} \\
C_{1}^{\prime}(Q), & \text { if } \tilde{Q}<Q
\end{array}\right.
$$

where $M C_{a}(Q)$ is strictly increasing. The quota $Q^{*}$ is given and is such that $\bar{q}_{3}<Q^{*}<\tilde{Q}$. In this case, generation costs are minimised producing $\left(q_{1}^{*}, q_{2}^{*}, q_{3}^{*}\right)=\left(0, q_{2}^{*}, \bar{q}_{3}\right)$, where $q_{2}^{*}=Q^{*}-\bar{q}_{3}$, and the marginal generation cost of the last unit of generation needed to comply with the quota is $M C^{*}=\frac{d C_{2}\left(q_{2}^{*}\right)}{d q_{2}}$ (optimal solution of Problem 1).

Let us assume for the moment that support is set at the level $M C^{*}$. The total costs of public support (falling to consumers) would be equal to $M C^{*} \times Q^{*}$ (the area below the line $M C^{*}$ and between 0 and $Q^{*}$ ). Part of this support from consumers covers the total generation costs, whereas the rest (the area between $M C^{*}$ and the aggregated marginal generation curve) represents the producer surplus. In this case, the specific mechanism of transfer of rents from consumers to producers is the producer surplus, and can be defined as $\left(T_{1}, T_{2}, T_{3}\right)$ such that

$$
T_{i}^{\prime}\left(q_{i}\right)=\left\{\begin{array}{cl}
M C^{*}-C_{i}^{\prime}\left(q_{i}\right), & \text { if } C_{i}^{\prime}\left(q_{i}\right) \leq M C^{*} \\
0, & \text { if } C_{i}^{\prime}\left(q_{i}\right)>M C^{*}
\end{array}\right.
$$

In this example, Problem 1 and Problem 2A have the same optimal solution. With this support mechanism, generation costs are minimised. However, it is possible to find other support mechanisms for which generation costs are also minimised but with lower consumer costs, such as the following:

$$
\bar{T}_{1}^{\prime}\left(q_{1}\right)=0, \quad \bar{T}_{2}^{\prime}\left(q_{2}\right)=\left\{\begin{array}{cc}
M C^{*}-C_{2}^{\prime}\left(q_{2}\right), & \text { if } 0 \leq q_{2} \leq q_{2}^{*} \\
0, & \text { if } q_{2}>q_{2}^{*}
\end{array}, \quad \bar{T}_{3}^{\prime}\left(q_{3}\right)=C_{3}^{\prime}\left(\bar{q}_{3}\right)-C_{3}^{\prime}\left(q_{3}\right)\right.
$$


For $\left(\bar{T}_{1}, \bar{T}_{2}, \bar{T}_{3}\right)$, Problem 1 and Problem $2 \mathrm{~A}$ have also the same optimal solution, but the consumer costs are lower than those corresponding to the producer surplus, that is mechanism $\left(T_{1}, T_{2}, T_{3}\right)$, because $C_{3}^{\prime}\left(\bar{q}_{3}\right)<M C^{*}$.

In this example, it has been assumed that the marginal generation costs are strictly increasing and therefore the transfers from consumers to producers (above the generation costs) are strictly positive, for each of the technologies and locations which are fully or partially deployed. If the function of marginal generation costs was a step function, the transfers from consumers to producers would be zero for all technologies and locations, when the mechanism $\left(\bar{T}_{1}, \bar{T}_{2}, \bar{T}_{3}\right)$ is used, and would even be zero for the most expensive among the technologies and locations deployed (corresponding to $i=2$ in this case), when the standard producer surplus is used. If some surplus is needed in order to make future RES-E investment attractive, other mechanisms have to be considered in this case.

\subsection{Minimisation of consumer costs does not imply that generation costs are minimised}

In the following example, the optimal solutions of problems 1 and $2 \mathrm{~A}$ are completely different.

Let us assume that the marginal costs are the following:

$$
\begin{aligned}
& C_{1}^{\prime}\left(q_{1}\right)=40, \text { for } 0 \leq q_{1} \leq 25 \\
& C_{2}^{\prime}\left(q_{2}\right)=42, \text { for } 0 \leq q_{2} \leq 30 \\
& C_{3}^{\prime}\left(q_{3}\right)=44, \text { for } 0 \leq q_{3} \leq 30
\end{aligned}
$$

The quota $Q^{*}=50$ is given. The optimal solution of Problem 1 is

$$
\left(q_{1}^{*}=\bar{q}_{1}=25, \quad q_{2}^{*}=25, \quad q_{3}^{*}=0\right) .
$$


Let us consider now the mechanism of transfer of rents from consumers to producers, defined by:

$$
\begin{aligned}
& T_{1}^{\prime}\left(q_{1}\right)=6, \quad \text { for } 0 \leq q_{1} \leq 25 \\
& T_{2}^{\prime}\left(q_{2}\right)=2, \quad \text { for } 0 \leq q_{2} \leq 30 \\
& T_{3}^{\prime}\left(q_{3}\right)=1, \quad \text { for } 0 \leq q_{3} \leq 30
\end{aligned}
$$

The optimal solution of Problem 2A is

$$
\left(q_{1}^{+}=0, \quad q_{2}^{+}=\bar{q}_{2}=30, \quad q_{3}^{+}=20\right) .
$$

Therefore, with this mechanism the generation costs are not minimised. In fact, the optimal solutions of problems 1 and $2 \mathrm{~A}$ are very different.

In Section 5, some mechanisms of transfer of rents from consumers to producers (different from the mechanisms used in Section 4) are presented, for which Problem 1 and Problem 2A have the same optimal solution.

\section{Some mechanisms for which Problem 1 and Problem 2A have the same optimal}

\section{solution}

In this section, two classes of mechanisms of transfer of rents from consumers to producers are proposed, which have the property that the optimal solution of problems 1 and $2 \mathrm{~A}$ is the same. They also permit a positive surplus to be given to all the technologies and locations which have to be deployed, even in the case of step functions for marginal costs. 


\section{Proposition 3.}

Let us assume that $\left(T_{1}, T_{2}, \ldots, T_{n}\right)$ is such that

$$
T_{i}^{\prime}\left(q_{i}\right)=\alpha C_{i}^{\prime}\left(q_{i}\right) \text {, where } \alpha>0, \alpha \in \square \text { is given } \text {. }
$$

Then, Problem 1 and Problem 2A have the same optimal solution, and moreover

$$
\tilde{C}\left(q_{1}^{*}, q_{2}^{*}, \ldots, q_{n}^{*}\right)=(\alpha+1) C\left(q_{1}^{*}, q_{2}^{*}, \ldots, q_{n}^{*}\right)
$$

The proof is in the Appendix.

With this proportional mechanism, the amount to be paid by consumers to each of the producers is equal to the cost of generation plus an additional rent which is a fixed proportion of the corresponding generation cost. Then, the higher the cost of the technology and location, the higher the transfer of rent from consumers to producers (assuming it is deployed).

\section{Proposition 4.}

Let us assume that $\left(T_{1}, T_{2}, \ldots, T_{n}\right)$ is such that

$$
T_{i}^{\prime}\left(q_{i}\right)=K \text {, where } K>0, K \in \square \text { is given } \text {. }
$$

Then, Problem 1 and Problem 2A have the same optimal solution, and moreover

$$
\tilde{C}\left(q_{1}^{*}, q_{2}^{*}, \ldots, q_{n}^{*}\right)=K Q^{*}+C\left(q_{1}^{*}, q_{2}^{*}, \ldots, q_{n}^{*}\right)
$$

The proof is in the Appendix.

With this constant mechanism, the amount to be paid by consumers to each of the producers is equal to the cost of generation plus an additional rent which is a fixed quantity per unit of production, independently of the cost of generation (assuming it is deployed).

Let us compare now the two mechanisms introduced in this section from the point of view of the consumer costs. Let us assume that $\alpha \in \square$ and $K \in \square$ are given, in such 
a way that each of the mechanisms give to producers enough surplus to make future RES-E investments attractive. Which of the two mechanisms leads to smaller costs for consumers? The answer is in the following proposition, which is easily obtained from Propositions 3 and 4.

\section{Proposition 5}

The constant mechanism (defined in Proposition 4) is better than the proportional mechanism (defined in Proposition 3) from the point of view of minimisation of consumer costs if and only if $\alpha C\left(q_{1}^{*}, q_{2}^{*}, \ldots, q_{n}^{*}\right) \geq K Q^{*}$. Otherwise, the proportional mechanism is better than the constant mechanism ${ }^{7}$.

The proof is in the Appendix.

\section{Conclusions}

This paper tries to contribute to the clarification of the meaning of "costeffectiveness" in the RES-E support literature, comparing the two main interpretations of cost-effectiveness regarding RES-E support. This clarification/comparison is important, given their policy relevance and the fact that rarely do supporters of one approach argue the same lines as those of the other approach. It allows us to take into account the conceptual framework and assumptions behind the analyses of those making proposals for specific instruments and design elements to support RES-E. In other words, it contextualises the contributions of those making policy prescriptions.

In this paper, the mathematical programming problems corresponding to each of the approaches have been formally defined and the corresponding optimality conditions have been obtained applying the Khun-Tucker conditions.

\footnotetext{
${ }^{7}$ If $\alpha C\left(q_{1}^{*}, q_{2}^{*}, \ldots, q_{n}^{*}\right)=K Q^{*}$ both mechanims are indifferent from that point of view.
} 
Some authors define the concept of cost-effectiveness as that which complies with the "equimarginal" principle, as defined in the environmental economics literature. However, we have seen in Proposition 1 that, strictly speaking, equimarginality is not necessarily satisfied by all the technologies and sites to be deployed. Same technologies and sites can be deployed in their entirety (when they have a bound) in such a way that the marginal cost of the last unit (corresponding to that technology and site) is smaller than the marginal cost corresponding to the point in which the aggregated marginal cost intersects the vertical line corresponding to the given quota for renewables.

Two simple counterexamples have been presented to show that 1) minimisation of generation costs does not imply that consumer costs are minimised, and, 2) minimisation of consumer costs does not imply that generation costs are minimised.

Two families of mechanisms of transfer of rents from consumers to producers for which the optimal solution in both approaches is the same have been proposed. The producers corresponding to the technologies and sites with higher marginal costs would prefer the proportional mechanism, the others would prefer the constant mechanism. These transfers account for less cost to the consumers than the standard producer surplus.

This paper has focused on static efficiency i.e., it has not considered technological changes or learning induced by RES-E support schemes, which would lead to a downward shift in the marginal cost curve for RES-E generation and, thus, lower policy costs, depending on whether consumers or producers benefit from those technological changes. Further research could analyse whether those shifts are really induced by the RES-E support instrument or by other factors, which instrument (FITs, TGCs or any other) is a more appropriate complement to public R\&D and is likely to induce technological changes better, the extent to which the aforementioned savings in policy 
costs (if any) offset the policy costs which induce those technological changes in the first place and whether those technological changes translate into lower policy costs (reductions in $\mathrm{MC}^{*}$ ) or a greater producer surplus.

The impact of different RES-E instruments on policy risks and, thus, on generation and policy costs should be the focus of further research, both theoretically (i.e., with formal models dealing with risks) and empirically (analysing those risks in countries with different instruments).

\section{Appendix}

\section{Proof of Proposition 1}

The optimal solution of Problem 1 has to satisfy the Kuhn-Tucker conditions, which are necessary conditions of local optimality. In order to apply these conditions, the corresponding Lagrange multipliers have to be introduced. Let's define the following Lagrange multipliers:

$\lambda$ is associated with the constraint $\sum_{i=1}^{n} q_{i}=Q^{*}$, therefore $\lambda^{*}=\frac{d C^{*}}{d Q}=M C^{*}$,

$\mu_{i}$ is associated with the constraint $0 \leq q_{i}$, for $i=1,2, \ldots, n$,

$\alpha_{i}$ is associated with the constraint $q_{i} \leq \bar{q}_{i}$, for $i=1,2, \ldots, n$.

The Lagrangian is

$L\left(q_{1}, q_{2}, \ldots, q_{n}, \lambda, \mu_{1}, \mu_{2}, \ldots, \mu_{n}, \alpha_{1}, \alpha_{2}, \ldots, \alpha_{n}\right)=\sum_{i=1}^{n} C_{i}\left(q_{i}\right)+\lambda\left[Q^{*}-\sum_{i=1}^{n} q_{i}\right]+\sum_{i=1}^{n} \mu_{i} q_{i}+\sum_{i=1}^{n} \alpha_{i}\left[q_{i}-\bar{q}_{i}\right]$

Let us apply now the Kuhn-Tucker conditions:

1) $\frac{\partial L}{\partial q_{i}}=C_{i}^{\prime}\left(q_{i}\right)-\lambda+\mu_{i}+\alpha_{i}=0$, for $i=1,2, \ldots, n$

2) a) $\sum_{i=1}^{n} q_{i}=Q^{*}$

b) $0 \leq q_{i} \leq \bar{q}_{i}$, for $i=1,2, \ldots, n$ 
3) a) $\mu_{i} \leq 0$, for $i=1,2, \ldots, n$

b) $\alpha_{i} \geq 0$, for $i=1,2, \ldots, n$

4) a) $\mu_{i} q_{i}=0$, for $i=1,2, \ldots, n$

b) $\alpha_{i}\left[\bar{q}_{i}-q_{i}\right]=0$, for $i=1,2, \ldots, n$

A) Let us assume that $q_{i}=0 \Rightarrow$ By $4 b$ ), it is $\alpha_{i}=0$.

By 2$)$, it is $\mu_{i} \leq 0$. Then, by 1$)$, we have $C_{i}^{\prime}(0)=\lambda-\mu_{i} \geq \lambda$.

Therefore, $q_{i}^{*}=0$, with $\mu_{i}^{*} \leq 0, \alpha_{i}^{*}=0, C_{i}^{\prime}(0) \geq \lambda^{*}$, satisfies conditions 1$\left.), 2 \mathrm{~b}\right), 3$ ) and 4).

B) Let us assume that $q_{i}=\bar{q}_{i} \Rightarrow$ By $4 a$ ), it is $\mu_{i}=0$.

By 2), it is $\alpha_{i} \geq 0$. Then, by 1$)$, we have $C_{i}^{\prime}(0)=\lambda-\alpha_{i} \leq \lambda$.

Therefore, $q_{i}^{*}=\bar{q}_{i}$, with $\mu_{i}^{*}=0, \alpha_{i}^{*} \geq 0, C_{i}^{\prime}\left(\bar{q}_{i}\right) \leq \lambda^{*}$, satisfies conditions 1$), 2$ b), 3) and 4).

C) Let us assume that $0<q_{i}<\bar{q}_{i} \Rightarrow$ By $4 a$ ), it is $\mu_{i}=0$, and by $4 b$ ) it is $\alpha_{i}=0$.

Then, by 1$)$, we have $C_{i}^{\prime}\left(q_{i}\right)=\lambda$.

Therefore, $q_{i}^{*} \in\left(0, \bar{q}_{i}\right)$, with $\mu_{i}^{*}=0, \alpha_{i}^{*}=0, C_{i}^{\prime}\left(q_{i}^{*}\right)=\lambda^{*}$, satisfies conditions 1$), 2 \mathrm{~b}$ ), 3) and 4).

Consequently, the solution $\left(q_{1}^{*}, q_{2}^{*}, \ldots, q_{n}^{*}\right)$, satisfying the Kuhn-Tucker conditions is such that $\sum_{i=1}^{n} q_{i}^{*}=Q^{*}$, with:

$q_{i}^{*}=0$, if $C_{i}^{\prime}(0) \geq \lambda^{*}$, with $\mu_{i}^{*} \leq 0$ and $\alpha_{i}^{*}=0$,

$q_{i}^{*}=\bar{q}_{i}$, if $C_{i}^{\prime}\left(\bar{q}_{i}\right) \leq \lambda^{*}$, with $\mu_{i}^{*}=0$ and $\alpha_{i}^{*} \geq 0$,

$q_{i}^{*} \in\left(0, \bar{q}_{i}\right)$, if $C_{i}^{\prime}\left(q_{i}^{*}\right)=\lambda^{*}$, with $\mu_{i}^{*}=0$ and $\alpha_{i}^{*}=0$.

The sufficient conditions are satisfied because the problem is convex: the objective function is convex (the addition of convex functions is also convex) and the feasible set 
is convex because all the functions defining the constraints are linear. Therefore, the Kuhn-Tucker conditions are also sufficient for global optimality

\section{$\underline{\text { Proof of Corollary } 1}$}

The proof is immediate, just taking $\alpha_{i}=0$, for $i=1,2, \ldots, n$ in the proof of Proposition 1

\section{Proof of Proposition 3}

$$
T_{i}\left(q_{i}\right)=\int_{0}^{q_{i}} T_{i}^{\prime}(x) d x=\int_{0}^{q_{i}} \alpha C_{i}^{\prime}(x) d x=\alpha C_{i}\left(q_{i}\right), \text { for } i=1,2, \ldots, n .
$$

Then, the objective function for Problem 2A is

$$
\begin{aligned}
& \tilde{C}\left(q_{1}, q_{2}, \ldots, q_{n}\right)=T\left(q_{1}, q_{2}, \ldots, q_{n}\right)+C\left(q_{1}, q_{2}, \ldots, q_{n}\right)=\sum_{i=1}^{n} T_{i}\left(q_{i}\right)+\sum_{i=1}^{n} C_{i}\left(q_{i}\right)= \\
& =\sum_{i=1}^{n} \alpha C_{i}\left(q_{i}\right)+\sum_{i=1}^{n} C_{i}\left(q_{i}\right)=(\alpha+1) \sum_{i=1}^{n} C_{i}\left(q_{i}\right)=(\alpha+1) C\left(q_{1}, q_{2}, \ldots, q_{n}\right),
\end{aligned}
$$

where $C\left(q_{1}, q_{2}, \ldots, q_{n}\right)$ is the objective function of Problem 1 .

As both problems have the same constraints, and their objective functions are related as has been shown in the previous lines, they have the same optimal solution and the Proposition holds

\section{Proof of Proposition 4}

$$
T_{i}\left(q_{i}\right)=\int_{0}^{q_{i}} T_{i}^{\prime}(x) d x=\int_{0}^{q_{i}} K d x=K q_{i}, \text { for } i=1,2, \ldots, n .
$$

Then, the objective function for Problem 2A is 


$$
\begin{aligned}
& \tilde{C}\left(q_{1}, q_{2}, \ldots, q_{n}\right)=T\left(q_{1}, q_{2}, \ldots, q_{n}\right)+C\left(q_{1}, q_{2}, \ldots, q_{n}\right)=\sum_{i=1}^{n} T_{i}\left(q_{i}\right)+\sum_{i=1}^{n} C_{i}\left(q_{i}\right)= \\
& =\sum_{i=1}^{n} K q_{i}+\sum_{i=1}^{n} C_{i}\left(q_{i}\right)=K \sum_{i=1}^{n} q_{i}+C\left(q_{1}, q_{2}, \ldots, q_{n}\right)
\end{aligned}
$$

where $C\left(q_{1}, q_{2}, \ldots, q_{n}\right)$ is the objective function of Problem 1 .

As both problems have the same constraints, and their objective functions are related as has been shown in the previous lines, they have the same optimal solution and moreover,

$$
\tilde{C}\left(q_{1}^{*}, q_{2}^{*}, \ldots, q_{n}^{*}\right)=K \sum_{i=1}^{n} q_{i}^{*}+C\left(q_{1}^{*}, q_{2}^{*}, \ldots, q_{n}^{*}\right)=K Q^{*}+C\left(q_{1}^{*}, q_{2}^{*}, \ldots, q_{n}^{*}\right)
$$

\section{Proof of Proposition 5}

The constant mechanism is better than the proportional mechanism from the point of view of minimisation of consumer costs if and only if the value of the objective function for the optimal solution, obtained in Proposition 4, is $\leq$ than the value of the objective function for the optimal solution, obtained in Proposition 3. That is, if and only if

$$
K Q^{*}+C\left(q_{1}^{*}, q_{2}^{*}, \ldots, q_{n}^{*}\right) \leq(\alpha+1) C\left(q_{1}^{*}, q_{2}^{*}, \ldots, q_{n}^{*}\right) \Leftrightarrow K Q^{*} \leq \alpha C\left(q_{1}^{*}, q_{2}^{*}, \ldots, q_{n}^{*}\right)
$$

\section{References}

Allan, G., Gilmartin, M., McGregor, P., Swales, K. 2011. Levelised costs of Wave and Tidal energy in the UK: Cost competitiveness and the importance of "banded" Renewables Obligation Certificates. Energy Policy 39(1), 23-39.

Aune, F., Dalen, H., Hagem, C. 2012. Implementing the EU renewable target through green certificate markets. Energy Economics 34, 992-1000. 
Bergek, A., Jacobsson, J. 2010. Are Tradable Green Certificates a cost-efficient policy driving technical change or a rent-generating machine? Lessons from Sweden 2003-2008. Energy Policy, 38(3), 1255-1271

Borestein, S. 2011. The Private and Public Economics of Renewable Electricity Generation. Energy Institute at Haas, WP 221R. Berkeley, California

Council of European Energy Regulators (CEER) 2012. Implications of Non-harmonised Renewable Support Schemes. A CEER Conclusions Paper. Ref: C12-SDE-2504b. Brussels.

Couture, T., Gagnon, Y. 2009. An Analysis of Feed-in Tariff Policy Design Options for Renewable Energy Sources. Universite de Moncton, Moncton, Canada.

de Jager, D., Klessmann, C., Stricker, E., Winkel, T., de Visser, E., Koper, M. Ragwitz, M., Held, A., Resch, G., Busch, S., Panzer, C., Gazzo, A., Roulleau, T., Gousseland, P., Henriet, M., Bouille, A. 2011. Financing Renewable Energy in the European Energy Market. Final Report. Ecofys. Utrecht.

Del Río, P. 2012. The dynamic efficiency of feed-in tariffs: the impact of different design elements. Energy Policy 41, 139-151.

Del Río, P., Cerdá, E. 2014. The policy implications of the different interpretations of the cost-effectiveness of renewable electricity support. Energy Policy 64, 364372.

Del Río, P. et al 2012. Pathways for a harmonised RES-E support scheme in the EU. IEE project beyond2020 - Design and impact of a harmonised policy for renewable electricity in Europe. http://www.res-policy-beyond2020.eu/ 
European Commission 2008. The support of electricity from renewable energy sources. Accompanying document to the Proposal for a Directive of the European Parliament and of the Council on the promotion of the use of energy from renewable sources. $\{\mathrm{COM}(2008) 19\}$. SEC(2008) 57. Brussels.

European Commission 2012. Renewable Energy: a major player in the European energy market. Communication from the Commission to the European Parliament, the Council, the European Economic and Social Committee and the Committee of the regions. $\operatorname{COM}(2012) 271$ final. Brussels 6.6.2012

Fürsch, M., Golling, C., Nicolosi, M., Wissen, R., Lindenberger, D. 2010. European RES-E Policy Analysis - A model based analysis of RES-E deployment and its impact on the conventional power market. Institute of Energy Economics at the University of Cologne (EWI).

Green, R., Yatchew, A. 2012. Support Schemes for Renewable Energy: An Economic Analysis. Economics of Energy \& Environmental Policy 1(2): 83-98.

Greenstone, M. and Looney, A. 2012. Paying Too Much For Energy? The True Costs of Our Energy Choices. Massachusetts Institute of Technology. Department of Economics. Working Paper Series.

Haas, R., Resch, G., Panzer, C., Busch, S., Ragwitz, M., Held, A. 2011. Efficiency and effectiveness of promotion systems for electricity generation from renewable energy sources. Lessons from EU countries. Energy 36(4), 2186-2193.

Heal, G. 2010. Reflections-The Economics of Renewable Energy in the United States”. Review of Environmental Economics and Policy 4(1), 139-154 
Huber C., T. Faber, R. Haas, G. Resch, J. Green, H. Cleijne, P.E. Morthorst, K. Skytte, M. Gual, P. Rio, A. Tacsir, M. Ragwitz, J. Schleich, W. Orasch, M. Bokemann, C. Lins 2004. Deriving optimal promotion strategies for increasing the share of RES-E in a dynamic European electricity market Green-X, founded by DG Research (FWP 5), Final report, forthcoming September 2004

International Energy Agency (IEA) 2011. Deploying Renewables, OECD/IEA, Paris.

Joskow, P. 2011. Comparing the costs of intermittent and dispatchable electricity generating technologies. EUI Working Papers RSCAS 2011/45. Robert Schuman Centre for Advanced Studies.

Klessmann, C., Held, A., Rathmann, M., Ragwitz, M. 2011. Status and perspectives of renewable energy policy and deployment in the European Union-What is needed to reach the 2020 targets? Energy Policy 39, 7637-7657.

Mendonça, M. 2007. Feed-In Tariffs: Accelerating the Deployment of Renewable Energy. Earthscan, London, UK.

Mitchell, C., J. L. Sawin, G. R. Pokharel, D. Kammen, Z. Wang, S. Fifita, M. Jaccard, O. Langniss, H. Lucas, A. Nadai, R. Trujillo Blanco, E. Usher, A. Verbruggen, R. Wustenhagen and K. Yamaguchi 2011. Policy, Financing and Implementation". In: IPCC Special Report on Renewable Energy Sources and Climate Change Mitigation [O. Edenhofer, R. Pichs-Madruga, Y. Sokona, K. Seyboth, P. Matschoss, S. Kadner, T. Zwickel, P. Eickemeier, G. Hansen, S. Schlomer, C. von Stechow (eds)], Cambridge, Cambridge University Press.

Nuclear Energy Agency and International Energy Agency, 2005. Projected costs of generating electricity. 
Ragwitz, M., Held, A. Resch, G., Faber, T., Haas, R., Huber, C., Coenraads, R., Voogt, M., Reece, G., Morthorst, P.E., Jensen, S.G., Konstantinaviciute, I., Heyder, B. 2007. OPTRES - Assessment and optimisation of renewable energy support schemes in the European electricity market. Brussels: supported by the European Commission (D.G. Energy and Transport); 2007.

Resch, G. et al. 2009. Action plan futures-e - Deriving a future European Policy for Renewable Electricity; Concise final report of the European research project futures-e (www.futures-e.org), supported by the EACI of the European Commission within the research programme "Intelligent Energy for Europe“. TU Wien, Energy Economics Group in cooperation with e.g. Fraunhofer ISI, Ecofys, EGL. Vienna, Austria, 2009, accessible at www.futures-e.org.

Schmalensee, R. 2011. Evaluating Policies to Increase the Generation of Electricity from Renewable Energy. MIT Center for Energy and Environmental Policy Research, Working Paper 2011-008.

Steinhilber, S., Ragwitz, M., Rathmann, M., Klessmann, C., Noothout, P. 2011. D17 Report: Indicators assessing the performance of renewable energy support policies in 27 Member States. RE-Shaping: Shaping an effective and efficient European renewable energy market

Teckenburg, E., Rathmann, M., Winkel, T., Ragwitz, M., Steinhilber, S., Resch, G., Panzer, C., Busch, S., Konstantinaviciute, I. 2011. Renewable Energy Policy Country Profiles. Prepared within the Intelligent Energy Europe project Contract no.: EIE/08/517/SI2.529243, www.reshaping-res-policy.eu 
Tietenberg, T. 2008. Environmental \& Natural Resource Economics: International Edition, 8/E Pearson Higher Education. ISBN-10: 0321560469. ISBN-13: 9780321560469.

Verbruggen, A. 2009. Performance evaluation of renewable energy support policies, applied on Flanders' tradable certificates system. Energy Policy 37(4), 13851394.

Verbruggen, A., Lauber, V. 2012. Assessing the performance of renewable electricity support instruments. Energy Policy, 45, 635-644 